\title{
PEQUI OIL PREVENTS CELL PROLIFERATION IN PROSTATIC EPITHELIUM OF GERBILS
}

\author{
Elisangela Paes Cardoso ', Khauara Lima Santos ', Sérgio Marcelino de Oliveira ${ }^{2}$, \\ Kallyne Kioko Oliveira Mimura ${ }^{2, *}$.
}

${ }^{1}$ Araguaia Valley University Center - UNIVAR, Barra do Garças, MT, Brazil.

${ }^{2}$ Laboratory of Histophysiology and Animal Reproduction - LaHRA, Federal University of Mato Grosso CUA/UFMT, Pontal do Araguaia, MT, Brazil.

*Correspondence author: kallynekom@gmail.com

\begin{abstract}
.
Introduction: The prostate is an exocrine gland regulated by testosterone. This gland is target of proliferative lesions, such as benign prostatic hyperplasia and cancer, which is related to the testosterone synthesis augment. The search for anticancer natural substances capable of preventing/treating proliferative lesions has fostered interest in therapeutic properties of Pequi (Caryocar brasiliense), known to be composed of various antioxidant, anti-inflammatory and anti-proliferative substances. Thus, the objective of this study was to verify the anti-proliferative property of pequi oil in the gerbil prostate under testosterone influence. Methodology: The animals were divided into the following groups: T (subcutaneous administration of testosterone cypionate; $T+P$ (pequi oil and testosterone cypionate) and Control (intact animals). After animal death, the prostates were collected and embedded in paraffin for Haematoxylin-Eosin stain, for histopathological evaluation, and antiPCNA immunostain for proliferative activity analysis. Results: Morphological analysis showed presence of stratification in the prostate epithelium of group T animals, accompanied by a high number of PCNA + cells, showing a high proliferative activity. In the $T+P$ group, the epithelium presented a pseudostratification pattern, with a smaller number of PCNA + cells, similar to the Control group, showing a decrease in proliferative activity and maintenance of the normal prostate tissue architecture when compared to the $T$ group. Conclusion: Our results show an anti-proliferative effect of pequi oil on the gerbil prostate under the influence of exogenous testosterone. Thus, pequi oil has great potential in the prevention of prostate proliferative lesions, such as cancer.
\end{abstract}

\section{Graphical Abstract}

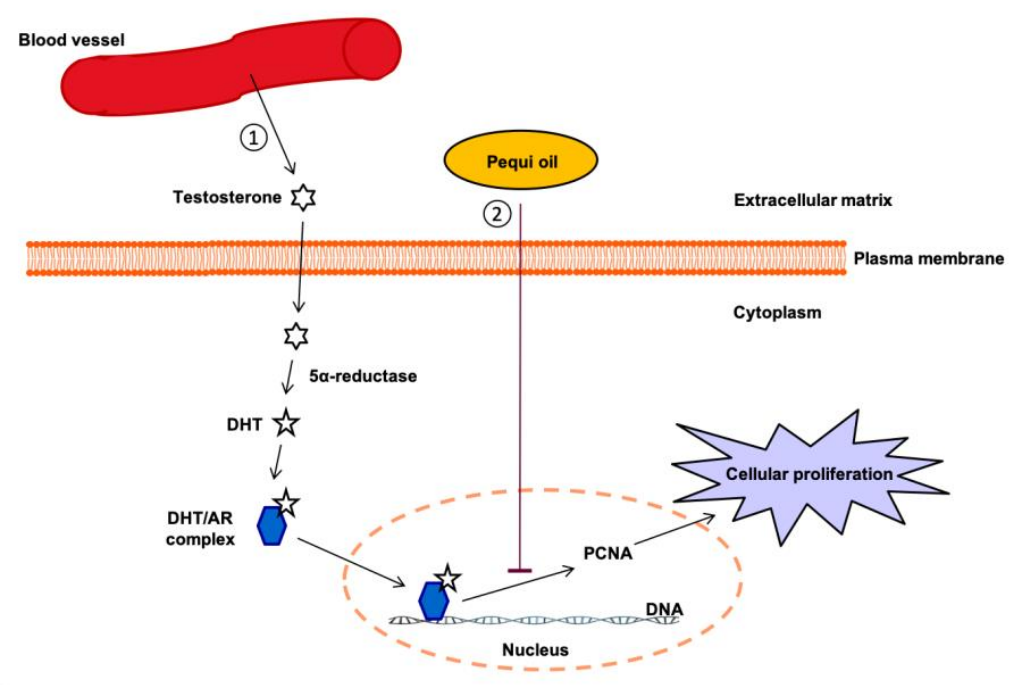

Grafical abstract figure. Schematic model of action mechanism of testosterone and pequi oil in prostatic cell. [1] The testosterone in peripheral blood diffuses through the plasma membrane and is converted to dihydrotestosterone (DHT) by $5 \alpha$-reductase. DHT binds to the androgen receptor (AR), which forms the DHT/AR complex. This complex is translocated to the nucleus and binding in DNA, trigging the transcription of PCNA that induces cell proliferation. [2] The treatment with pequi oil is able to block PCNA synthesis (Scheme adapted from Wadosky and Koochekpour [4]). 


\section{Introduction}

The prostate is a branched alveolar tubule gland situated in the true pelvis and plays a supportive role in the male reproductive system. This gland secretes the prostate fluid, an alkaline solution that acts to balance the acidity of the vagina and contains supportive proteins and enzymes that provide nourishment to sperm [1]. The morphology and physiology of this gland are regulated by testosterone, which is related to the appearance of proliferative lesions, such as benign prostatic hyperplasia and cancer [2]. This hormone diffuses across the plasma membrane of the prostate epithelial cells where it is converted to dihydrotestosterone (DHT) by $5 \alpha$-reductase [3]. The DHT binds to androgen receptors (AR), forming a complex that is translocated to the nucleus, where induces a transcriptional profile that causes general cell processes, including growth, proliferation and survival [4]. Several researches have searched for natural substances capable of preventing and / or reversing the pathological processes involved in the appearance and progression of prostate proliferative lesions [5]. Among these phytotherapics we can highlight Pequi (Caryocar brasiliense), a typical fruit of the Cerrado, that is composed of several antioxidant, anti-inflammatory, anti-proliferative substances, which are related to the reduction and suppression of pre-neoplastic lesions [6]. Therefore, the purpose of our study was to verify the possible anti-proliferative property of pequi oil in the gerbil prostate under testosterone influence.

\section{Materials and Methods}

15 male gerbils (60 days old) were divided into 3 groups $(n=5)$ : i) Control, intact animals; ii) $\mathrm{T}$, received subcutaneous administration of $0.10 \mathrm{~mL}$ of testosterone cypionate for 90 days at $48 \mathrm{~h}$ intervals; and iii) $\mathrm{T}+\mathrm{P}$, received pequi oil ( $1 \mathrm{~mL} / \mathrm{kg})$, by gavage, daily for 120 days, starting on day 0 , plus testosterone cypionate (similar to group T), starting on day 30. The prostatic fragments were fixed for $4 \mathrm{~h}$ in Metacarn, dehydration in graded alcohol, embedding in paraffin wax and sectioned at $5 \mu \mathrm{m}$. The sections were stained with Hematoxylin-Eosin, for histopathological evaluation, and submitted to immunohistochemical staining with PCNA antibody, for proliferative activity evaluation. Results were shown as mean \pm SEM and statistical significance was defined as $\mathrm{p} \leq 0.05$.

\section{Results and Discussion}

Morphological analyzes in the prostate tissue of the Control group animals (Figure 1A) showed acini composed of simple cubic / columnar epithelium, surrounded by smooth muscle and, more externally, by connective tissue rich in blood vessels. After testosterone application (group T; 
Figure 1B) the prostate tissue architecture was altered, with several foci of epithelial stratification. The prostate of animals that received treatment with pequi oil together with the application of testosterone (group T+P; Figure 1C) presented fewer tissue morphology alterations than group $\mathrm{T}$, with less epithelial stratification.
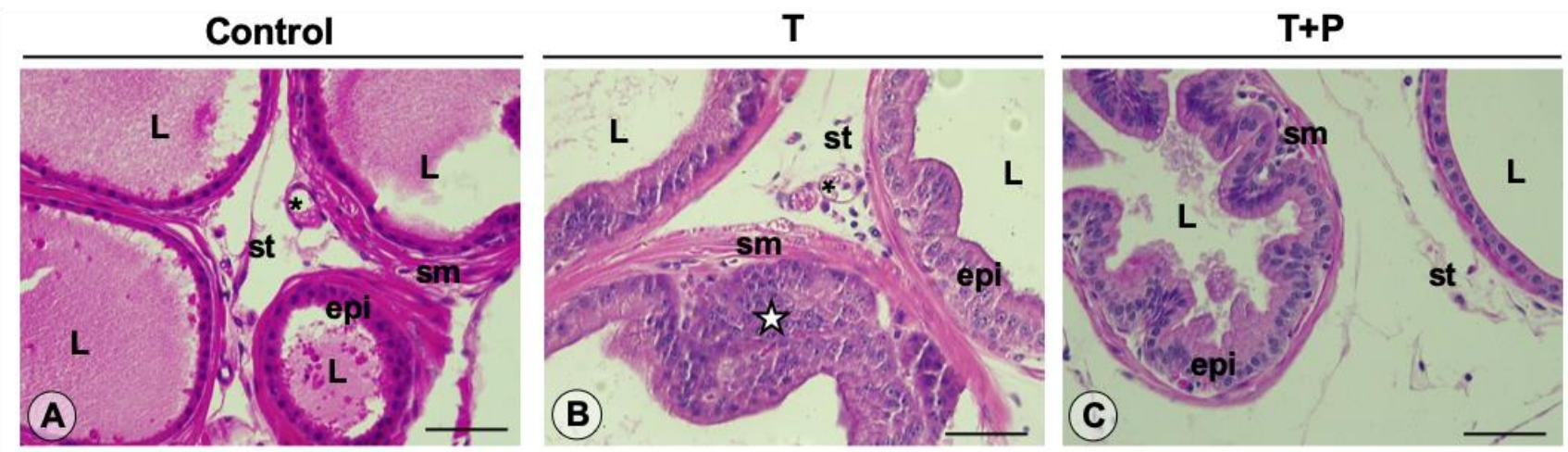

Figure 1. Morphological analysis of prostate of Control $[\mathbf{A}], \mathrm{T}[\mathbf{B}]$ and $\mathrm{T}+\mathrm{P}[\mathbf{C}]$ groups. L (lumen), st (stroma), epi (epithelium), sm (smooth muscle), * (blood vessel), star (epithelial stratification region).

Staining: Hematoxylin-Eosin. Bar: $50 \mu \mathrm{m}$.

The immunohistochemistry to PCNA positive cells detection (Figure 2) revealed that testosterone (group T; Figure 2A) promoted a significant increase in the proliferative cells amount compared to the Control group ( $\mathrm{p} \leq 0.001$; Figures $2 \mathrm{C}$ and D). Moreover, pequi oil (group T+P; Figure 2B) reversed this situation ( $\mathrm{p} \leq 0.001$ ), keeping the amount of PCNA positive cells similar to the Control group (Figures 2C and D). These data corroborate the review published by [7] that exhibit the antiproliferative properties of this compound. In addition, studies show that the antiproliferative potential of pequi may be related to the large amount of antioxidant substances that this fruit possess $[8,9]$. The oxidative damage is directly related to the carcinogenesis process, since reactive oxygen species can act at all stages of the proliferation process [10]. 

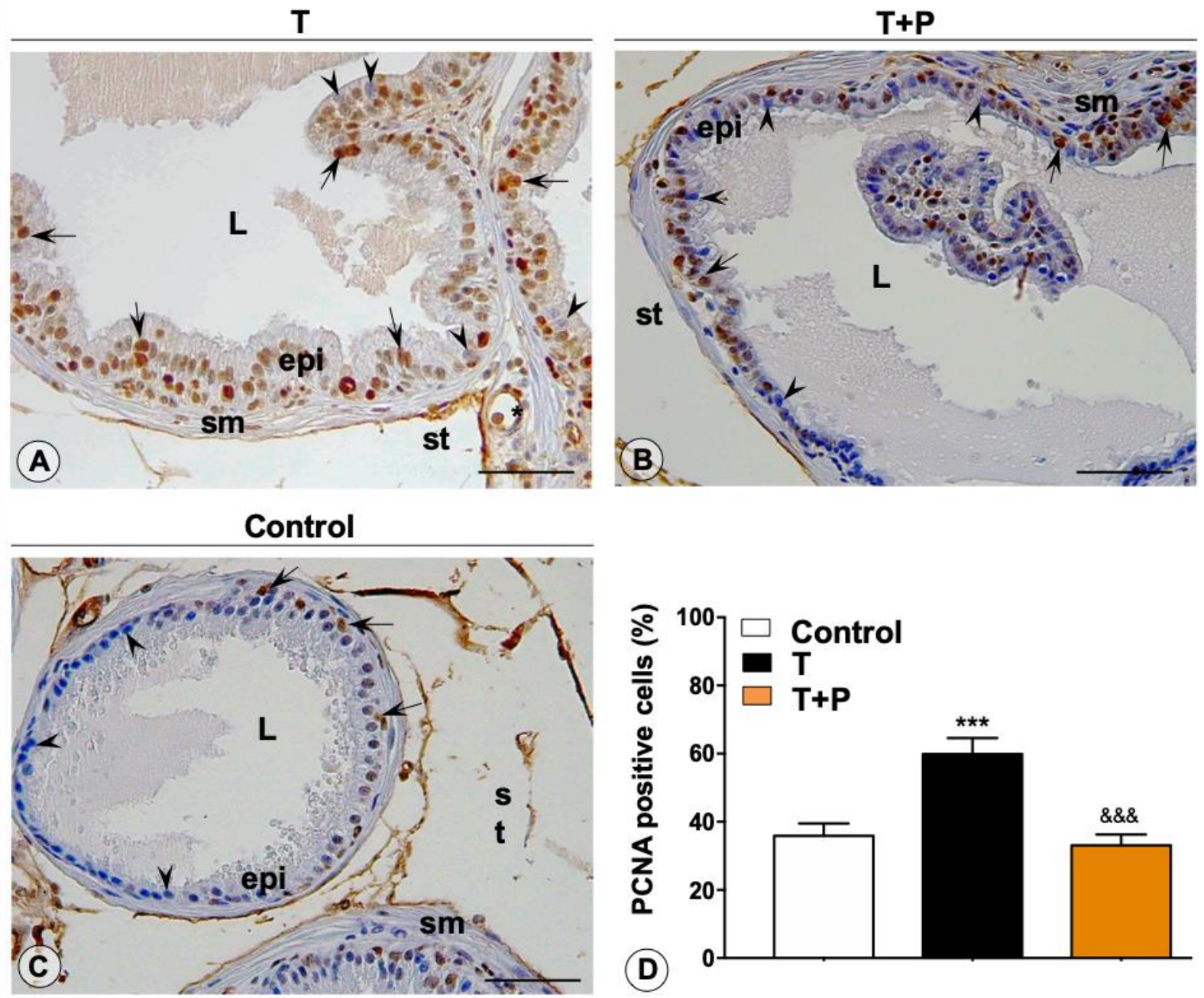

Figure 2. Immunohistochemistry analysis of proliferative cells of $\mathrm{T}[\mathbf{A}], \mathrm{T}+\mathrm{P}[\mathbf{B}]$ and Control [C] groups. Arrow (PCNA positive cell), arrowhead (PCNA negative cell), L (lumen), st (stroma), epi (epithelium), sm (smooth muscle), * (blood vessel). Quantitative analysis of PCNA + cells of the prostatic epithelium [D]. Data show mean \pm S.E.M. percentage of positive PCNA cells. *** $\mathrm{p} \leq 0.001$ versus Control group; $\& \& \& \mathrm{p} \leq 0.001$ versus $\mathrm{T}$ group. Counterstaining: Harris Hematoxylin. Bar: 50 $\mu \mathrm{m}$.

\section{Conclusions}

Altogether, these data show that pequi oil has an effective antiproliferative effect in the gerbil prostate under exogenous testosterone influence. Thus, pequi oil has great potential in the prevention of prostate proliferative lesions, such as prostate cancer. In addition to highlight the importance of preserving Cerrado species, since pequi is a typical plant of this biome.

\section{References}

[1] Singh, O.; Bolla, R. S. StatPearls Publishing 2019.

[2] Tortora, J.; Derrickson, G. B. Princípios de Anatomia e Fisiologia. 14. ed. Rio de Janeiro: Koogan, Guanabara 2016. 
[3] Heemers, H. V.; Tindall, D. J. Endocrine reviews 2007, 28, 778.

[4] Wadosky, M. K.; Koochekpour, S. Int. J. Biol. 2016, 12, 409.

[5] Brandão, H. N., et al. Quím. Nova. 2010, 33, 1359.

[6] Palmeira, S. M., et al. European Journal of Cancer Prevention 2016, 25, 299.

[7] Bailão, E. F. L. C., et al. Int. J. Mol. Sci. 2015, 16, 23760.

[8] Miranda-Vilela, A. L., et al. J. Nutr. Biochem. 2014, 25, 1161.

[9] Roll, M. M., et al. Genetics and Molecular Biology 2018, 41, 858.

[10] Waris, G.; Ahsan, H. Journal of Carcinogenesis 2006, 5. 